\title{
The effects of infill wall on dynamic characteristics of reinforced concrete frame systems
}

\author{
M.A. Kömür* İ.Ö. Deneme, M.A. Kara \\ Aksaray University, Department of Civil Engineering, Aksaray, Turkey
}

\begin{abstract}
This study presents an experimental investigation on the dynamic characteristics of infilled Reinforced Concrete (RC) frames. For this purpose, a 1/3-scaled, one-bay, three-storey RC frame was produced and tested by using ambient vibration test. The experiments were performed on sequentially produced three specimens which use the same single reinforced frame. The infill walls were made of hollow clay brick. The frequency, mode shapes and damping ratios in the in-plane direction of patterns were obtained by six accelerometers. Fifteen-minute records under ambient vibration were taken for each model, and the dynamic characteristics were determined using the ambient response testing and modal identification software (ARTeMIS) program. The experiments showed that the infill walls significantly affected the frequency values and damping ratios of the frame system. As a result of this study, the presence of damaged/undamaged infill walls lead to an increase in the frequency values and the damping ratios for the first three modes of the frame systems. On the other hand, the natural frequency of the first three modes of with undamaged infill walls is more than those with damaged ones. While the damping ratios for undamaged infill walls were increased at first two modes and it was decreased at the third mode.
\end{abstract}

\section{Keywords}

Ambient vibration test; Reinforced concrete frame; Infill wall; Damage

Received: 26 July 2019; Accepted: 24 September 2019

ISSN: 2630-5763 (online) C 2019 Golden Light Publishing ${ }^{\circledR}$ All rights reserved.

\section{Introduction}

The earthquakes occurred up to present showed that the majority of the buildings in Turkey have a weak seismic behavior. These are mainly due to insufficient material usage, architectural design faults, workmanship faults and insufficient usage of the stirrup bars and concrete class. These causes have adverse effects on the seismic performance of the buildings. It is extremely important to predict the problems that may arise and to take the necessary precautions. Operational modal analysis (OMA) is a very effective method to accomplish these purposes.
OMA has become a popular method in the last two decades. It is widely preferred in different engineering disciplines such as mechanical engineering, civil engineering and aerospace engineering. It has particularly been widely used to experimentally determine the dynamic characteristics of high-rise buildings, historical bridges and other structures. It is a non-destructive method based on the principle of the measuring the influences of ambient vibrations on the structure, which is used to determine the dynamic characteristics. In this method, environmental effects such as traffic, wave, wind, and tremors etc.

\footnotetext{
Corresponding author

E-mail: makomur@aksaray.edu.tr
} 
are used as input. Due to some advantages of this method such as the determination of dynamic characteristics under actual service conditions, while not interrupting the use of structure during measurement, and being a quick and economic method, it is popularly used [1].

The dynamic characteristics of a structure might be determined by experimental and analytical methods. Since the analytical models that are made do not fully reflect the actual behavior of the building, real dynamic characteristics cannot be obtained due to the support conditions, the mass of structures and etc. To obtain more accurate results in analytical studies, researchers have made both experiments performed on full-scale constructions in the field and in experimental studies on scaled constructions in the laboratory conditions [2-9]. For this reason, experimental methods are needed to create a finite element model that will represent actual behavior.

In the design of the RC buildings, while the effects of the infill wall were applied as a load on the beams, the contribution to the stiffness is neglected. Therefore, the effects of infill wall on the dynamic characteristics are not fully represented. The experimental studies have shown that dynamic characteristics are significantly affected by infill wall [10-14]. For this reason, taking into account the infill wall effect in the analytical model will lead to a better representation of the behavior of the building.

In this study, the aim was to determine the effects of infill wall and damaged infill wall, which might be occurred by external effects on dynamic characteristics of the frame system. Therefore, onebay, three-storey frame system was produced using different stages such as, bare frame, with infill wall and damaged infill wall and the OMA method were performed. In the experimental study, Enhanced Frequency Domain Decomposition (EFDD) was used to determine the dynamic characteristics.

\section{Materials and methods}

\subsection{Operational modal analysis method}

OMA is a non-destructive method to determine the dynamic characteristics of a structure such as modal shape, natural frequency, and damping ratio. In this method, the environmental effects such as traffic, wave, and tremors etc. are used as input.

OMA method is investigated under two phases which are time domain and frequency domain. While in the time domain decomposition method, the free response available at all time intervals is considered, in Frequency Domain Decomposition (FDD), a small frequency range in which a mode dominates in each mode is considered. Therefore, FDD method has an advantage of modal decomposition comparing with time domain decomposition [15].

FDD is an algorithm to identify the modal properties and it was first formulated by [16]. The EFDD technique is an extension of the Frequency Domain Decomposition (FDD) technique. The FDD technique is based on using a single frequency line from the fast Fourier transform analysis, the precision of the estimated natural frequency depends on the fast Fourier transform resolution, and no modal damping ratio is calculated in FDD. However, the EFDD technique provides an improved estimation of the natural frequencies and mode shapes including the damping ratios [17]. Also, the estimation of the modal shapes and natural frequencies is better by comparison with damping ratios in EFDD method. The estimation of the damping ratios was discussed, the new methods were compared with each other, and a method was proposed in order to get more reliable results in the damping ratio estimation [18].

\subsection{Experimental study}

In this study, a 1/3-scaled, one-bay, three-storey RC frame was produced and tested by using OMA. The experiments were performed on three specimens: one reference bare frame and two frames with infilled undamaged/damaged walls (Figs 1-3). The bay of the frame system was $1.4 \mathrm{~m}$ and the height was $2.65 \mathrm{~m}$. The dimension of column was $10 \times 15$ 
$\mathrm{cm}$ and the dimension of the beam was $10 \times 10 \mathrm{~cm}$. In the beams and columns of the frame system, $4 \square 8$ longitudinal steel bars and $\square$ 4-diameter stirrups were used. Stirrups were placed in central zone with $5 \mathrm{~cm}$ and in the confinement zone with $2.5 \mathrm{~cm}$ spaced evenly. The foundation of the frame system was considered as rigid and the foundation-column joint was designed as a fixed-support.

The concrete used for frame system was prepared in laboratory and developed by mixing fine aggregate, coarse aggregate, cement and water. The weight mixture ratios of the fine aggregate $(0$ $7 \mathrm{~mm})$, coarse aggregate $(7-15 \mathrm{~mm})$, cement and water materials in used concrete as $28.9 \%, 149.2 \%$, $13.3 \%$ and $8.6 \%$, respectively.

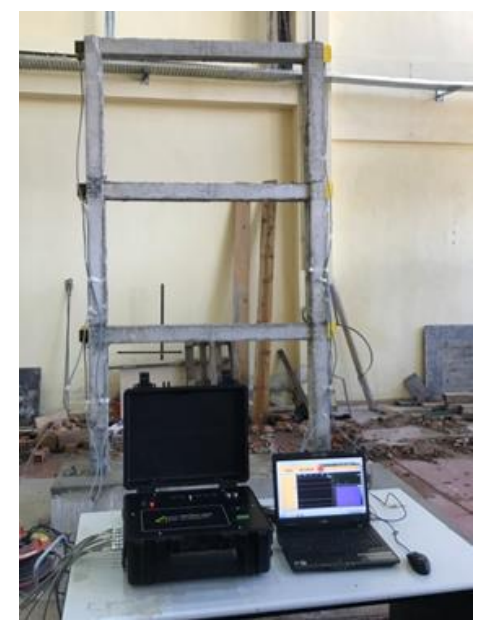

Fig. 1. Bare frame

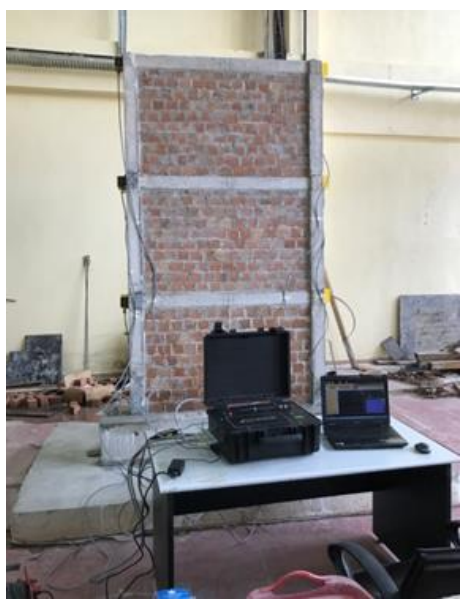

Fig. 2. Frame with undamaged infill wall

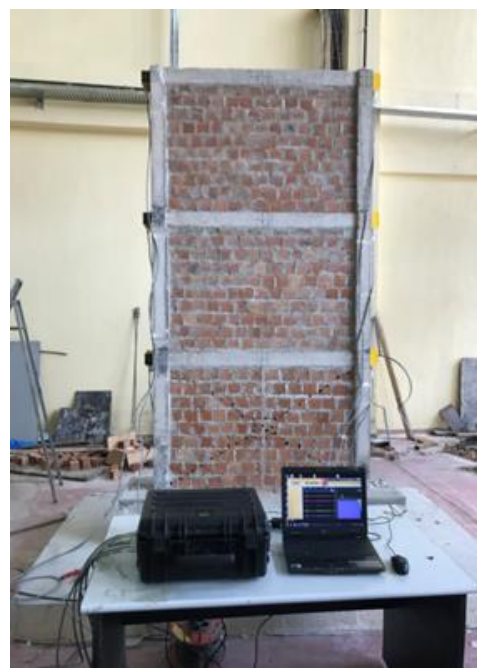

a) General view

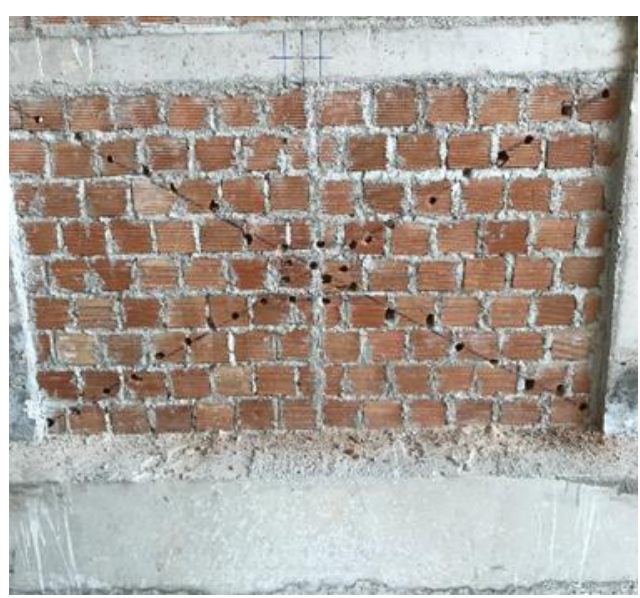

b) Detail view of damaged 1st storey

Fig. 3. Frame with damaged infill wall

To determine the compressive strength of $\mathrm{C} 25$ concrete, 5 cubic specimens $(150 \times 150 \times 150 \mathrm{~mm})$ were acquired and held in a curing tank for 28 days. The cube specimens were subjected to an axial pressure test using a $2000 \mathrm{kN}$ capacity loading device. The 28-day average compressive strength of the concrete was calculated to be $33.04 \mathrm{MPa}$.

Horizontal hollow clay bricks with sizes of $72 \times 90 \times 82 \mathrm{~mm}$ was used in the infill walls of the frame system. The uniaxial pressure tests were carried out parallel and perpendicular to the hollows for determining the compressive strength of the bricks. The average results, 9.70 $\mathrm{MPa}$ and 
6.37 MPa for parallel and perpendicular to the hollows, were obtained as compressive strength values, respectively.

The mortar used for the infill wall masonry was developed by mixing sand, cement, lime and water. The weight mixture ratios of the sand, cement, lime and water materials in used mortar as $60 \%, 11 \%$, $11 \%$ and $18 \%$, respectively. Three cubic specimens $(50 \times 50 \times 50 \mathrm{~mm})$ were employed to determine the compressive strength of the mortar material. The specimens were subjected to a pressure test and the obtained average result was $4.05 \mathrm{MPa}$ as compressive strength value. Mixed mortar with a thickness of $5 \mathrm{~mm}$ was used in the infill wall joints. The first storey infill wall of the frame system was damaged by a jackhammer.

OMA was used for determining the dynamic characteristics as modal shape, natural frequency and damping ratio of three different patterns. The dynamic characteristics of the patterns in the inplane direction were obtained by 6 pieces SENSEBOX7021 type accelerometers. The properties of accelerometers are given in Table 1 . The ambient vibrations, generated by environmental excitations, were measured by seismic accelerometers fixed to the column-beam joints. Twenty-minute records under ambient vibration were taken for each model in the range of 0-250 Hz. The measured vibration signals were recorded via a 20-channel TESTBOX-6501 data logger unit and processed in the TESTLAB NETWORK software. Then, the dynamic characteristics were obtained by using EFDD method in ARTeMIS software [19].

Table 1. Technical Specifications of SENSEBOX7021 type accelerometer

\begin{tabular}{ll}
\hline $\begin{array}{l}\text { Max. acc. measurement } \\
\text { interval }\end{array}$ & $\pm 3 \mathrm{~g}$ \\
Noise density & $130 \mathrm{ng} / \sqrt{ } \mathrm{Hz}$ \\
Sensitivity & $2400 \mathrm{mV} / \mathrm{g}$ \\
Frequency interval & $0-1200 \mathrm{~Hz}$ \\
Shock resistance & $2000 \mathrm{~g}$ \\
Excitation voltage & $\pm 6-15 \mathrm{VDC}$ \\
Operating temperature & $-55-+65^{\circ} \mathrm{C}$ \\
\hline
\end{tabular}

\section{Results and discussion}

\subsection{Determining modal parameters of bare frame system}

To determine the dynamic characteristics of the bare frame system in the in-plane direction, 6 accelerometers were used which were fixed to the column-beam joints. Then, ARTEmIS software was used for analyzing the vibration data which were obtained from data acquisition unit. With this software, a model representing the frame system was created and vibration data were identified to the points by means of sensors. In the software, by use of EFDD, the spectral density matrix was obtained for first three modes (Fig. 4). In Fig. 4, the peak points represent vibration resonance of the structure and the frequency value of each resonance indicates the natural frequency of the structure. Using the frequency values of the peak points, the modal damping ratio of the building is obtained by different methods. The mode shapes that represent the modal behavior of the building are derived from the real parts of the function of each peak value [20].

Mod shapes, natural frequencies, and damping ratios obtained from experimental measurement of frame system are shown in Fig. 5.

\subsection{Determining modal parameters of frame system with undamaged infill wall}

In ARTEmIS software, by using EFDD method, spectral density matrix was obtained and shown in Fig. 6.

Modal shapes, natural frequency values and damping ratios which were obtained from experimental measurements shown in Fig. 7.

\subsection{Determining modal parameters of frame system with damaged infill wall}

The first storey of the infilled wall frame system was damaged in diagonal directions by using a jackhammer. The vibration data obtained with the help of accelerometers placed in this system were transferred to ARTEmIS software. The spectral density matrix was obtained by using of EFDD method and shown in Fig. 8. 


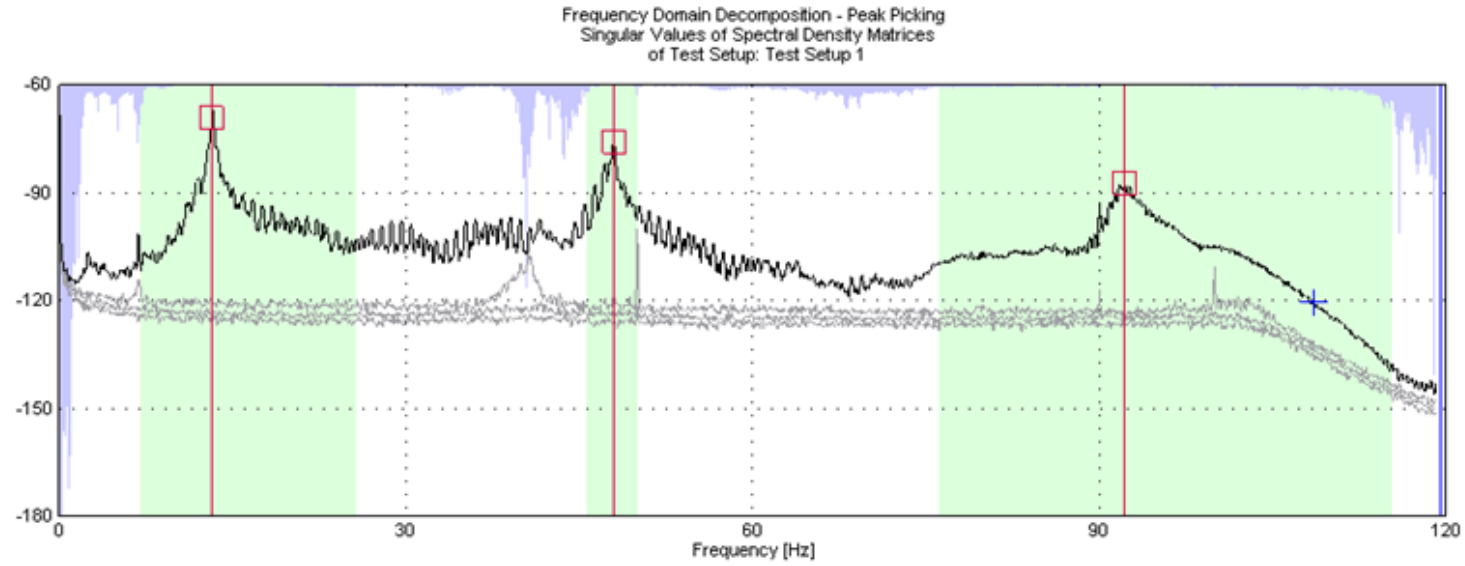

Fig. 4. Singular values of each modal shapes of bare frame system

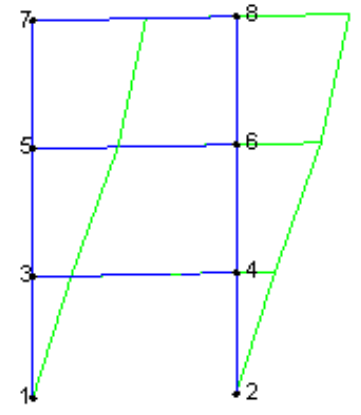

$\mathrm{f}=12.76 \mathrm{~Hz} \xi=1.153$

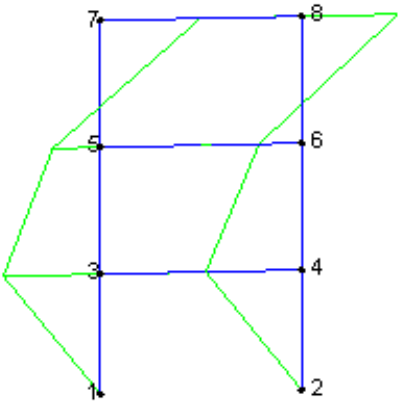

$\mathrm{f}=47.47 \mathrm{~Hz} \xi=0.674$

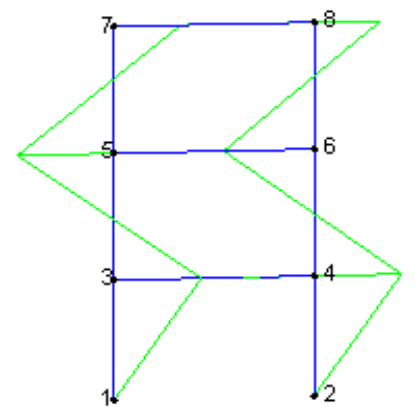

$\mathrm{f}=90.90 \mathrm{~Hz} \quad \xi=0.7829$

Fig. 5 Modal shapes, frequency values and damping ratios of the frame system

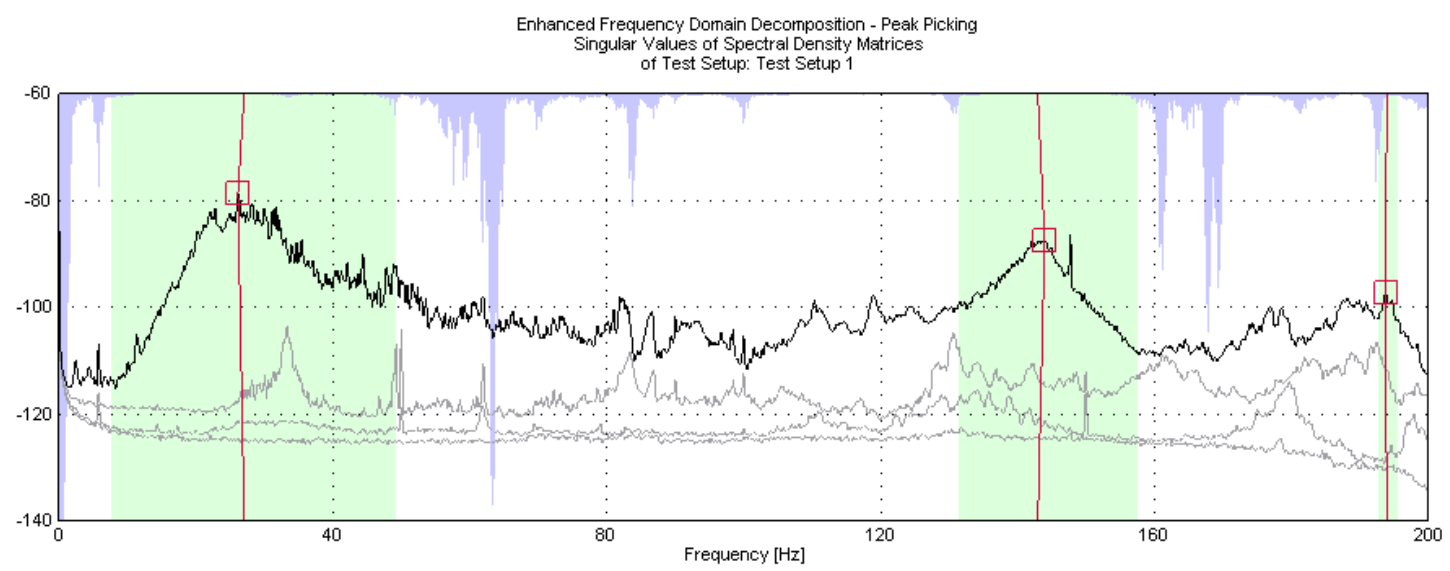

Fig. 6. Singular values of each modal shapes of the frame system with infill wall 


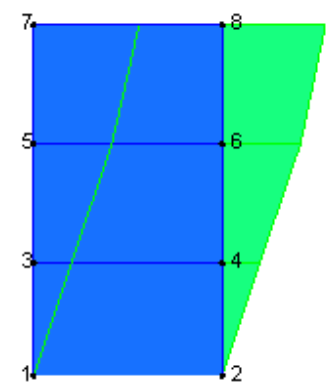

$\mathrm{f}=26.74 \mathrm{~Hz} \xi=5.259$

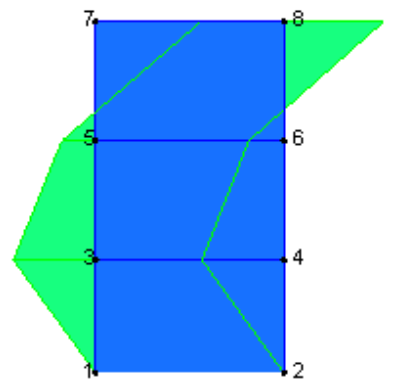

$\mathrm{f}=142.7 \mathrm{~Hz} \xi=2.445$

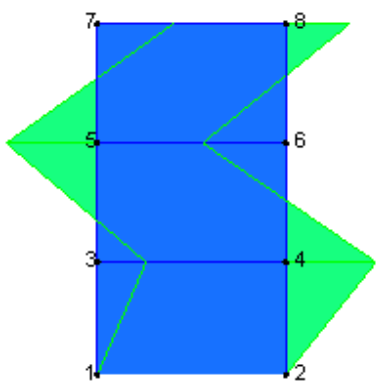

$\mathrm{f}=193.8 \mathrm{~Hz} \quad \xi=0.92$

Fig. 7. Modal shapes, natural frequency values and damping ratios of undamaged frame system

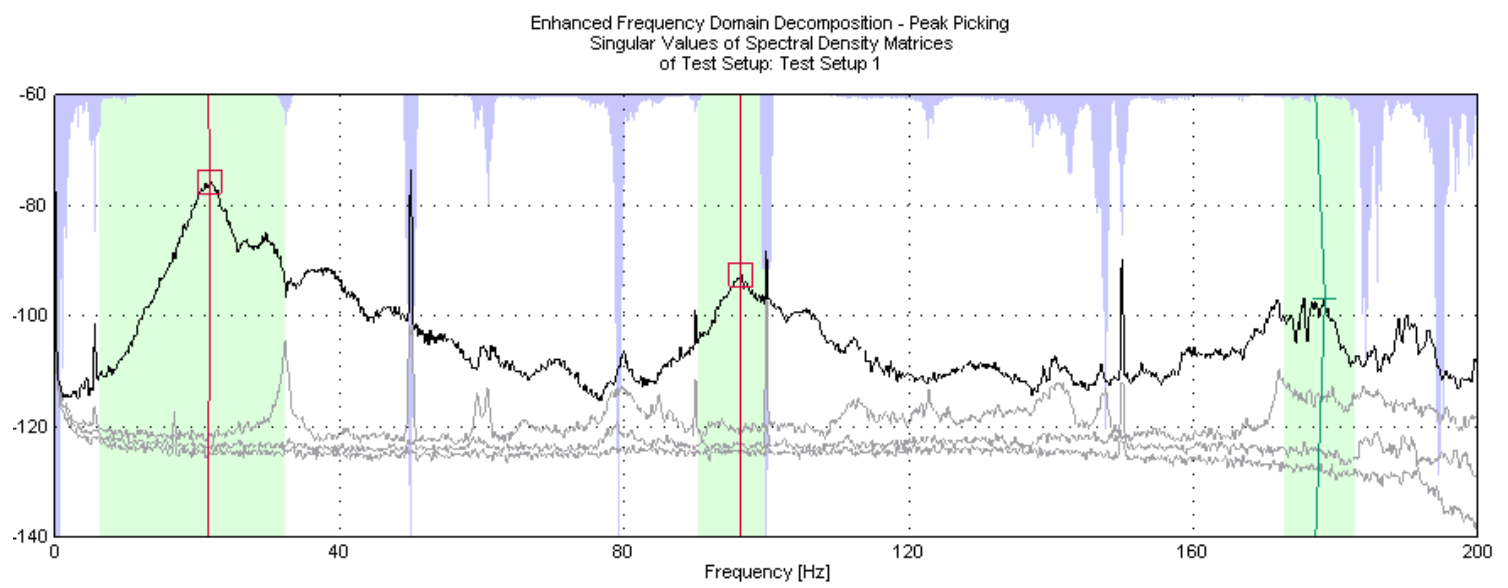

Fig. 8. Singular values of each modal shapes of frame system with damaged first storey infill wall

Modal shapes, natural frequencies and damping ratios of the damaged frame system obtained from the experimental measurements are shown in Fig. 9. Frequency values and damping ratios for the first three modes were summarized in Table 2.

The frequency values of the first three modes of the frame system with undamaged infill wall increased by \%109.56, \%200.61 and \%113.2, respectively, compared to the frequency values of the bare frame system. Similarly, when the damping ratios were considered, the damping ratios of the frame system with undamaged infill wall increased compared to the bare frame system. On the other hand, frequency values of the frame system with damaged infill wall decreased by $\% 20.08, \% 32.51, \% 8.62$, respectively, compared to the undamaged condition.

When the damping ratios of the bare frame system and the infill wall frame system were compared, the damping ratios of the infill wall frame system increased in all three modes. The damping ratios of the first-floor infill wall damaged frame system with reference to undamaged infilled frame system wall ones were decreased in the first two modes and increased in the third mode. If the three measured models are compared, it can be said that the minimum damping ratios occurs in the bare frame system and the maximum damping ratios occurs in the undamaged infill wall case. Modal assurance criterion (MAC) was used to determine the relationship between mode shapes of the damaged and undamaged infill frame systems. According to the MAC values, given in Fig. 10 and Table 3, the second mode is the most sensitive to damage. On the other hand, the high correlation is obtained in the first mode. 


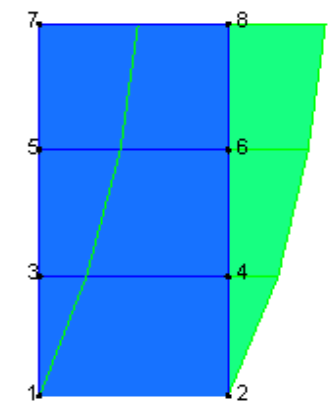

$\mathrm{f}=21.37 \mathrm{~Hz} \xi=3.509$
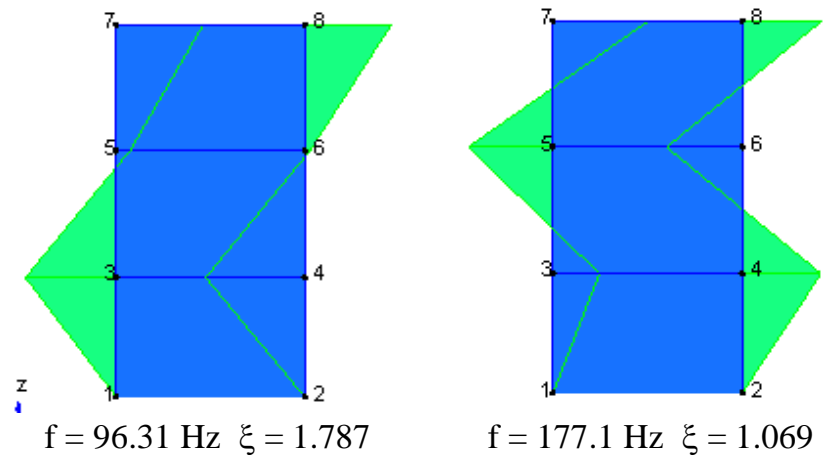

$\mathrm{f}=177.1 \mathrm{~Hz} \quad \xi=1.069$

Fig. 9. Modal shapes, natural frequency values and damping ratios of damaged frame system

Table 2. Frequency values and damping ratios

\begin{tabular}{lcccccc}
\hline & \multicolumn{2}{c}{ Bare frame } & \multicolumn{2}{c}{ With undamaged infill wall } & \multicolumn{2}{c}{ With damaged infill wall } \\
\cline { 2 - 6 } Mode & Frequency & $\begin{array}{c}\text { Modal } \\
\text { Damping Ratio }\end{array}$ & Frequency & $\begin{array}{c}\text { Modal } \\
\text { Damping Ratio }\end{array}$ & Frequency & $\begin{array}{c}\text { Modal } \\
\text { Damping Ratio }\end{array}$ \\
\hline 1 & 12.76 & 1.153 & 26.7 & 5.259 & 21.37 & 3.509 \\
2 & 47.47 & 0.674 & 142.7 & 2.445 & 96.31 & 1.787 \\
3 & 90.90 & 0.783 & 193.8 & 0.92 & 177.1 & 1.069 \\
\hline
\end{tabular}

Table 3. MAC (Damaged and undamaged infill wall frame system)

\begin{tabular}{|c|c|c|c|c|}
\hline \multirow{2}{*}{\multicolumn{2}{|c|}{ Mode no }} & \multicolumn{3}{|c|}{ Undamaged } \\
\hline & & 1 & 2 & 3 \\
\hline \multirow{3}{*}{ 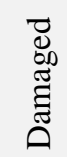 } & 1 & 0.991 & 0.032 & 0.025 \\
\hline & 2 & 0.124 & 0.879 & 0.037 \\
\hline & 3 & 0.085 & 0.128 & 0.935 \\
\hline
\end{tabular}

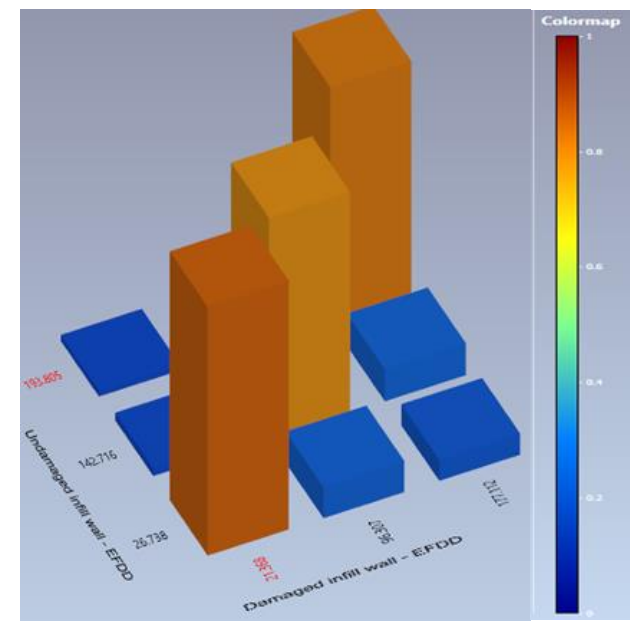

Fig. 10. MAC (Damaged and undamaged infill wall frame system)

\section{Conclusions}

In this study, the dynamic characteristics of a $1 / 3$ scaled, one-bay, three-storey RC frame system were determined in three different conditions such as bare frame, with undamaged infill wall and damaged infill wall. The results of the study were presented below.

- The infill wall significantly increased the stiffness of the system, therefore for each three modes, natural frequency values and damping ratios increased.

- The damaged infill wall caused to decrease the stiffness. Consequently, the frequency values decreased compared with the undamaged condition. However, while the modal damping ratios decreased in the first two modes it increased in the third mode.

- It is understood that the infill wall significantly influences the dynamic characteristics of the frame system. Considering the infill walls in the analysis of the structures by the finite element method will also provide a more realistic representation of the behavior of the building. 
- Modal assurance criterion (MAC) was used to determine the relationship between mode shapes of the damaged and undamaged infill wall frame systems. This criterion shows that the second mode shape is the most sensitive mode to damage.

\section{Acknowledgements}

This research was supported by the Institute of Research Management, Aksaray University under Research Grant No. 2015-024.

\section{References}

[1] Rainieri C, Fabbrocino G. Operational Modal Analysis of Civil Engineering Structures: An Introduction and Guide for Applications. Springer New York Heidelberg Dordrecht London, 2014.

[2] Chaker AA, Cherifati A (1999) Influence of masonry infill panels on the vibration and stiffness characteristics of R/C frame buildings. Earthquake Engineering and Structural Dynamics 28(9): 10611065.

[3] Sevim B, Bayraktar A, Altunışık AC, Adanur S, Akköse M (2010) Modal parameter identification of a prototype arch dam using enhanced frequency domain decomposition and stochastic subspace identification techniques. Journal of Testing and Evaluation 38(5): 588-597.

[4] Sevim B, Altunışık AC, Bayraktar A (2012) Experimental evaluation of crack effects on the dynamic characteristics of a prototype arch dam using ambient vibration tests. Computers and Concrete 10(3):277-294.

[5] Arslan ME, Durmuş A (2014) Modal parameter identification of in-filled RC frames with low strength concrete using ambient vibration. Structural Engineering and Mechanics 50(2): $137-$ 149.

[6] Kaplan O, Guney Y, Doğangün A, Livaoğlu R. Effect of infill walls and plaster for a four storey $\mathrm{R} / \mathrm{C}$ building. $6^{\text {th }}$ International Operational Modal Analysis Conference (IOMAC), 12-14 May 2015, Gijón, Spain.

[7] Timurağaoğlu MO, Livaoğlu R, Doğangün A. Investigation of the infill wall effect on the dynamic behaviour of RC frames. $6^{\text {th }}$ International Operational Modal Analysis Conference (IOMAC), 12-14 May 2015, Gijón, Spain.

[8] Türker T, Bayraktar A (2017) Vibration based modal testing of a scaled reinforced concrete building for construction stages. Bulletin of Earthquake Engineering 15(8): 3399-3416.

[9] Günaydin M, Adanur S, Altunişik AC, Sevim B, Bayraktar A (2017) Finite modeling updating effects on the dynamic response of building models. Journal of Testing and Evaluation 45(5): 1630-1649.

[10] Boru EO, Kutanis M (2015) Determination of structural dynamic parameters with ambient vibration measurements (in Turkish). Sakarya University Journal of Science 19(1): 59-66.

[11] Bikçe M, Geneş MC, Zubaroğlu SKA. Dynamic tests of a reinforced concrete structure with and without infilled wall1 (in Turkish). Turkey Earthquake Engineering and Seismology Conference, 11-14 October 2011, Ankara.

[12] Masi A, Vona M (2010) Experimental and numerical evaluation of the fundamental period of undamaged and damaged RC framed buildings. Bulletin of Earthquake Engineering 8(3): 643-656.

[13] Guler K, Yuksel E, Kocak A (2008) Estimation of the fundamental vibration period of existing RC buildings in Turkey utilizing ambient vibration records. Journal of Earthquake Engineering 12(2): $140-150$.

[14] Oliveira CS, Navarro M (2010) Fundamental periods of vibration of RC buildings in Portugal from in-situ experimental and numerical techniques. Bulletin of Earthquake Engineering 8(3): 609-642.

[15] Brincker R, Ventura C. Introduction to Operational Modal Analysis. John Wiley \& Sons, Ltd., 2015.

[16] Brincker R, Zhang L, Andersen P. Modal identification from ambient responses using frequency domain decomposition, $18^{\text {th }}$ International Modal Analysis Conference, 7-10 February 2000, Texas, USA.

[17] Jacobsen NJ, Andersen P, Brincker R. Using Enhanced Frequency Domain Decomposition as a Robust Technique to Harmonic Excitation in Operational Modal Analysis, 18-20 September 2006, Lueven, Belgium.

[18] Rainieri C, Fabbrocino G, and Cosenza E (2010) Some remarks on experimental estimation of damping for seismic design of civil constructions. Shock and Vibration 17(4-5): 383-395.

[19] ARTeMIS Ambient Response Testing and Modal Identification Software, Version Modal 1.5, 2013.

[20] Brincker R, Ventura CE, Andersen P. Damping estimation by frequency domain decomposition. Proceeding of IMAC 19: A Conference on Structural Dynamics, 5-8 February 2001, Florida, USA. 